\title{
Exploration and Practice of "Smart Campus" Construction of Local Universities in Economically Underdeveloped Areas-Taking Guangdong Ocean University as an Example
}

\author{
Guangya Zhang1,* \\ ${ }^{1}$ Educational Information Center, Guangdong Ocean University, Zhanjiang, China \\ *Corresponding author. Email: zhanggy@gdou.edu.cn
}

\begin{abstract}
Information technology has revolutionary influence on education development. As a place where tens of thousands of teachers and students live, work and study, the university campus has a high requirement for information construction. New technology and new application mode are greatly changing the traditional campus information construction. Based on the latest related technologies in the Internet industry and the information status of Guangdong Ocean University, combined with the theory and knowledge of project management, the author puts forward the goal of the construction of intelligent campus, makes a plan for the smart campus construction, and elaborates in detail on the specific construction contents of the intelligent campus from the aspects of information standard, infrastructure, application system, service-oriented resource sharing support platform and information security system, and then puts forward the implementation plan of construction of the intelligent campus for the specific content, in order to improve the service level of teaching, scientific research, management in our university.
\end{abstract}

Keywords: smart campus; project management; mobile Internet technology

\section{INTRODUCTION}

In the early stage of campus information construction, the main goal is to realize the network office of each department business system with the help of campus network, namely "Digital Campus". However, there is a lack of a unified management platform, each business system is independent of each other, data is not connected, which leads to the problems of resource waste, data island, and so on. "Smart campus" is the upgraded version of "Digital Campus", benefits from the progress of mobile communication technology and the wide spread of mobile devices, its information service ability has been further expanded and improved [1].

The "14th Five-Year" period (2021-2025) is the key period for Guangdong Ocean University to fully implement the spirit of 19th CPC National Congress and Xi Jinping's socialist ideology with China's characteristics for a new era. It is the key period to implement the overall plan for the comprehensive reform in education, implement the education informatization 2.0 action plan, and comprehensively enhance the level of intelligence education. Combined with the actual development of our university, the education information center is comprehensively promoting the construction of smart campus to meet the growing needs of teachers and students.

\section{PROBLEMS IN THE CONSTRUCTION OF SMART CAMPUS}

After years of information construction, education informatization has been well developed in in Guangdong Ocean University. However, with the continuous expansion of enrollment scale, the continuous improvement of teachers and students' information service requirements, the level of smart campus is more and more dependent on information infrastructure and application system. At present, compared with the requirements of our university's reform and development, there is still a big gap between information infrastructure and application system and the expectations of teachers and students. It mainly includes the following aspects:

\subsection{Lack of talents in informatization construction}

At present, the talent team of informatization construction is difficult to meet the technical requirements of each department business system. The number of posts and the team structure are difficult to meet the requirements of network security and ideological security under the current situation. With the continuous increase of system operation, maintenance and management business, it is necessary to 
speed up the improvement of information technology support team that can meet the needs of smart campus construction.

\subsection{Infrastructure construction needs to be strengthened}

The contradiction between infrastructure and application demand is becoming increasingly prominent, including full coverage of wireless network, wired access infrastructure equipment, limited computing resources in cloud Resource Center, aging of some equipment, lag in capacity expansion and update, lack of advanced means in the production of course video resources.

\subsection{The overall planning of informatization construction is insufficient}

The information system of each department is constructed in a decentralized way, lacking a unified management platform, and there are security risks and performance bottlenecks, which can't ensure the effective sharing of data.

\subsection{Information security needs to be improved}

The evaluation of network security level protection shows that there are still many security problems in the key information infrastructure, and corresponding rectification measures need to be implemented. According to the network security level protection 2.0 standard, actively carry out the filing work of information system security level protection. According to the standard, the system, computer room and network structure are transformed, and the network security level protection of important systems is put on record.

\subsection{Lack of high-quality education resources}

There is no self-built national teaching resource, provincial teaching resources are not very sufficient. The construction of network training platform and virtual simulation teaching resources need to be further strengthened.

\section{GOAL OF INTELLIGENT CAMPUS CONSTRUCTION IN GUANGDONG OCEAN UNIVERSITY}

Our university's overall goal of the intelligent campus construction is to build an intelligent, flexible and efficient campus system. Gradually realize all-round interaction of teaching, comprehensive perception of environment, efficient coordination of management, personalized convenience of campus life, and finally build a complete and unified, advanced technology, comprehensive coverage, indepth application, efficient and stable, safe and reliable smart campus. The specific objectives are as follows:

\subsection{Personnel training}

First of all, the student-centered academic planning and guidance system is established, and the digital and intelligent guidance service platform of our university is constructed. Secondly, with the construction of "golden course" as the center and "Ideological and political education" as the starting point, the online and offline integration and intercommunication mode are adopted to create the intelligent education and teaching space. Third, the combination of virtual and real, production and teaching cooperation, make full use of industrial cooperation and social resources, improve the diversified practice education platform, and improve students' practical ability. Fourth, build a data platform for curriculum quality management, carry out experiential and intelligent evaluation of teaching quality, conduct intelligent analysis of course quality based on big data, establish intelligent supervision mechanism, and then form a multi-level quality assurance system.

\subsection{Scientific research and discipline construction}

To build a comprehensive information platform for scientific research, realize the collection, transmission, storage, processing, maintenance and application of scientific research information, and realize the management and service of the whole life cycle of scientific research projects in our university. Through the high-quality data analysis, leader can get the advantages and development bottlenecks of our discipline construction, and receive some development suggestions of our university based on the data support.

\subsection{Personnel management}

Break the boundaries of departments, integrate the personnel management related business of multiple administrative departments, and build a comprehensive personnel platform for resource integration and data sharing. To obtain the data and information of scientific research, teaching, equipment, finance, etc., make reasonable and effective use of them. Through the business mutual correlation, promote the collection and improvement of the data of staff, simplify the redundant links in the business process, ensure the accuracy and real-time of the data, realize business management and service by using fragmented services, and improve the user's experience.

\subsection{Student management}

Collect the information of students' status, e-mail, rewards and punishments, financial aid, achievements, etc., to form a comprehensive and accurate database of students' basic information, so as to assist the smooth and efficient development of student work business. At the same time, it provides centralized personal data center services for 
students, and provides reliable and convenient dependence for students to strengthen self-management.

\subsection{Administrative office}

According to our university's actual office logic, on the premise of ensuring the rigor of the business process, we adopt the fragmented service concept to deal with the business in a very simple way, and track the task processing process in real time, so as to facilitate the user to implement the business, reduce the difficulty of transaction coordination, and improve the efficiency of business processing.

\subsection{Campus life}

Our university will build a new service platform of dormitory, catering, maintenance information, provide mobile visual query of parking space and vehicle information, realize campus intelligent parking, constantly improve the living environment construction of teachers and students, and improve their satisfaction.

\section{CONTENTS OF INTELLIGENT CAMPUS CONSTRUCTION IN GUANGDONG OCEAN UNIVERSITY}

According to the construction goal of smart campus, combined with the actual situation of our university, the education information center adopts the service-oriented architecture to carry out smart campus construction, including information standard, infrastructure, application system and resource sharing support platform, and so on.

\subsection{Information standards}

Information standard construction is one of the key points of smart campus construction, which is of great significance to ensure the exchange and sharing of information. After years of information construction, our university has formed a set of school information standards and accumulated a lot of business data. With the development of information technology and the adjustment of university business, it is necessary to reorganize and plan the information standards and data quality, and redefine the information standards from the perspective of service and openness, so as to make it extensible and persistent.

\subsection{Infrastructure}

Through years of network construction, there are two export lines of campus network in our university, which are China Education and research computer network (CERNET) and China Telecom network. The CERNET is 10 Gbps interconnection, and the user export bandwidth of China
Telecom campus network is 40 Gbps. The wired network coverage has laid a good foundation for the online operation of multimedia courseware, the implementation of distance education, the realization of office automation and the modernization of teaching management. With the increasing number of mobile terminals, wireless network has become the main form of campus network development. With the help of wired and wireless network technology, the coverage and application scope of campus network can be expanded, so that teachers and students can use the campus network conveniently and efficiently at anywhere, so as to promote the development of teaching and scientific research, improve the management level and efficiency, and promote the informatization construction of the school.

With the continuous increase of business requirements and hardware equipment, the application system is becoming more and more complex, which results in low utilization rate of system resources and difficulties in operation and maintenance management. Based on the virtualization technology, our school has built a cloud data center, which provides hardware support for various applications in campus informatization.

\subsection{Smart campus application system}

The purpose of information construction is to comprehensively improve the service quality of teaching, learning, scientific research, management and life of teachers and students. The realization of its functions can't be separated from various application systems. Therefore, in the construction process of smart campus, the construction of application system will run through the whole construction cycle, and will be continuously optimized and improved.

\subsection{Service-oriented resource sharing support platform}

The purpose of the construction of campus resource sharing support platform is to eliminate the "information island" between business application systems in our university. Through the integration of interface, process and data, the service-oriented resource sharing support platform connects the business processes, realizes the interconnection of various business application systems, and provide one-stop service channel for teachers and students.

\subsection{Information security system}

The implementation of information security system construction can ensure the coordinated development of information security and smart campus, and strengthen information security management. Its construction content mainly includes physical security construction, network security construction, host security construction, application security construction and data security construction. 


\section{IMPLEMENTATION SCHEME OF SMART CAMPUS CONSTRUCTION IN GUANGDONG OCEAN UNIVERSITY}

In the process of our smart campus construction, the overall design embodies the concepts of "unified platform", "data centralization", "service-oriented", "business modularization", and so on. At the same time, in the implementation process of the scheme, the development and deployment are carried out in strict accordance with the idea of "overall planning, step-by-step implementation, strengthening application, integrating resources and sharing data".

\subsection{Information standard construction}

Information standard is the basis of the whole campus information construction, and is the necessary condition to realize the exchange and sharing of educational information resources within the whole campus. The construction scheme adopted by our university is: basing on the national standards, the Ministry of education standards, industry standards and our existing standards, taking into account the compatibility, consistency and scalability of various standards, to improve various standards of our university, and form a set of management informatization standards in line with the actual situation.

\subsection{Infrastructure construction}

The education information center will promote the construction of integrated access to campus network based on the next generation Internet IPv6, providing a variety of access means such as wired, wireless and mobile, especially the end-to-end integration of Internet of things, 5g and IPv6, providing greater freedom in space and time for the service capacity of campus network resources, realizing the full coverage of IPv6 and IPv4 dual stack network, and fully meeting the requirements of the whole school The requirements of bandwidth and mobility for teachers and students in learning, teaching and research and work.

In the data center construction, the end-to-end data center virtualization technology planning and design is adopted, including computing pool, network pool, storage pool, virtualization security, cloud management platform, etc. We will strengthen the construction of data center, upgrade, strengthen and optimize various operating systems and application business operation environment of the data center, and expand the computing and storage resources of cloud platform (simultaneously increase authorization of more than 48 physical CPUs for virtual cloud grid security protection). We will optimize the management mode of cloud platform to realize dynamic and intelligent resource management. We will build a dual active disaster recovery data center, complete data integration and disaster recovery protection, meet the requirements of data security and system high availability, at the same time, classify and classify the business data of the data center, and establish data backup management system and backup mechanism.

\subsection{Application system constructios}

During the construction and implementation of the application system, the technical department and business departments participate together. The project is organized by the education information center, and the business departments lead and control the demand to ensure that the implementation results of the project can meet actual needs. The implementation steps are as follows.

1) We will complete the upgrading of campus card system and the construction of information infrastructure such as multimedia classroom, video monitoring and video conference system, and improve the sharing degree of information and resources. Taking the construction of new teaching building as an opportunity, combined with the actual situation, we will build a number of demonstration smart classrooms, truly promote the learning support environment of online and offline integration, and provide advanced teaching methods for teaching reform.

2) We will build an intelligent live and recording platform for classroom. The live broadcast and recording of classroom teaching can be completed automatically, and the recorded teaching videos can be automatically stored in the teaching resource management library, which is conducive to the rapid increase of our network teaching resources in a short period of time.

3) We will Complete the construction of educational administration, scientific research, office, school work, assets, finance, logistics and other application systems, realize the integration of various application systems in data, identity authentication, application release, and realize the intelligence of information service.

4) With mobile applications as the carrier, such as mobile client, relying on mobile internet technology, we will build a diversified and open mobile campus platform, a mobile campus portal.

\subsection{Support platform construction}

The supporting platform mainly includes data center, unified identity authentication and unified information portal. We should standardize the whole process of information collection, processing, exchange and comprehensive utilization, establish a safe, efficient and fully shared data center, and provide efficient information services for teaching management and personnel training. The unified identity authentication platform provides a unified authorization mechanism and a set of convenient and safe password authentication methods, so that users can use all the application systems within their authority on the campus network, as long as they have a set of user name and password. The construction of information portal platform will aggregate the scattered and heterogeneous applications and information resources, realize seamless access and 
integration of various application systems through a unified access portal, provide an integrated environment supporting information access, transmission and cooperation, and realize the efficient development, integration, deployment and management of personalized business applications.

\subsection{Information security system construction}

Our university must fulfil the security protection obligations in accordance with Network security law of the people's Republic of China and National network security level protection system 2.0 national standard. Our university takes the filing of the evaluation of network security level protection of information system as a normal work. Information security system is built on the basis of physical safety construction, and the information security protection system [6] covering network security, host safety, application security and data security is completed by means of a safe and reliable computer room information environment. It is supplemented by a perfect management and operation system, which ensures the continuity and advanced nature of the information security protection system.

\section{CONSTRUCTION ACHIEVEMENTS}

The bidding of "cooperation between bank and university Smart Campus Construction " has been completed, and 47.86 million construction funds have been obtained. The cloud platform construction of virtualization resources has been completed. The network information security system of data center has been built, including the upgrading of system security, information security, security management, security audit and so on. It has completed the renovation of the computer room infrastructure of our university data center, as well as the network export and disaster recovery computer room construction in Xiashan campus. The campus network transformation based on the next generation Internet technology (IPv6) has been completed. The construction of the whole network security situation awareness, security protection of operation and maintenance platform have been completed. The first phase of website cluster system construction has been completed, including the construction of software and hardware environment for website group management and support, management standard system for website group construction and operation, etc., which has effectively improved the security protection and control capabilities of our university website. The online service hall of Guangdong Ocean University has been completed and put into use. The assessment score of our university on the information technology work management platform of the Ministry of education is the first, within Guangdong Province. Our network security work has been praised by the Guangdong Education Department.

\section{CONCLUSION}

The construction of smart campus is the inevitable trend of the development of education informatization, and it is a huge system engineering of university informatization. During the construction of smart campus, Guangdong Ocean University has done a good job in top-level design and overall planning, formulated plans in line with its own development, and built a "One-Station" Information resource service platform with mobile Internet as the carrier, so as to improve the service level of teaching, scientific research, management in our university.

\section{ACKNOWLEDGMENT}

This study was funded by the fourth batch of non-funded technology research projects in Zhanjiang in 2019 No $2019 B 01230$.

\section{REFERENCES}

[1]Huang Ronghuai, Zhang Jinbao, Hu Yongbin \& Yang Junfeng. Smart Campus: The Developing Trends of Digital Campus [J]. Open Education Research ,2012,18(4):12-17. (In Chinese)

[2]Chen Yongjian \& Cong Qing. Wireless mesh network and application techniques[J]. Computer and Information Engineering College,2010,(13):3369-3372. (In Chinese)

[3]Qiu Huiqi, Chen Shiping \& Zhu Yuhong. Research resource sharing and service cooperative between universities in region model based on SOA[J]. Application Research of Computers, 2010, (01):197199. (In Chinese)

[4]Chen Kejia. Machine learning techniques in social network analysis: A survey [J]. Journal of Nanjing University of Posts and Telecommunications (Natural Science), 2011, (03):83-90. (In Chinese)

[5]Chen Cuizhu \& Huang Ronghuai. Research on "Web-based" smart campus and its system construction [J]. Journal of Fujian institute of

Education,2012,18(1):120-124. (In Chinese)

[6]Wang Xue. Analysis on the Hidden Dangers of Information System in Universities and the Preventive Measures [J]. Journal of Jilin Agricultural Science and Technology College,2017,26(1):41-43. (In Chinese) 